\title{
The pandemic ushers in a new view of economic activity and innovation policy
}

This paper was downloaded from TechRxiv (https://www.techrxiv.org).

LICENSE

CC BY 4.0

SUBMISSION DATE / POSTED DATE

09-02-2022 / 12-02-2022

\section{CITATION}

Litwin, Andrej; Fölster, Stefan (2022): The pandemic ushers in a new view of economic activity and innovation policy. TechRxiv. Preprint. https://doi.org/10.36227/techrxiv.19149152.v1

DOI

10.36227/techrxiv.19149152.v1 


\title{
The pandemic ushers in a new view of economic activity and innovation policy
}

\author{
Stefan Fölster, Andrej Litwin
}

\begin{abstract}
The pandemic has precipitated a shift of value creation toward economic activity that is ignored in measures of economic growth such as GDP. As a consequence, economic policy is increasingly fumbling in the dark. Not least innovation policies and growth-oriented $R \& D$ now lack a relevant yardstick of success. This article provides an overview of the challenge and suggests better ways to measure the impact of innovations. Ultimately this concerns what kind of development nations aim for and how they assess success.
\end{abstract}

Index Terms - Pandemic, technological innovation, economic growth, innovation policy.

\section{INTRODUCTION}

Decades of digitalization, with a remarkable explosion in performance and functionality of digital technology as predicted by Moore's law, have not left any significant footprint on GDP (Gross Domestic Product) and productivity growth as they are measured in official national accounts. In the aftermath of the pandemic the disconnect is likely to become even more accentuated.

Economists and other social scientists have always known that economic growth as defined in terms of [monetary] value added or GDP misses many aspects of quality of life such as health, a sound environment or social justice. A new reality, expedited by the pandemic, is that not even economic value creation is captured well. That has potentially grave consequences. The benefits of innovation are underestimated. Innovative countries appear less successful than countries that expand production of traditional products. New measures that better capture value creation would lend support to more ambitious innovation policies.

Economic growth today is defined as a monetary increase of value added created in the production of goods and services. It has tended to increase by a few percent per capita and year globally and probably reflects short term economic fluctuations well enough. Yet to many economists it remained a mystery that the remarkable explosion in performance and functionality of digital technologies has not left much of a footprint on GDP growth or productivity. In the early 2000s this paradox was confounded by the so called "productivity paradox". Productivity development throughout the world slowed down. The new pattern also included an unusually low inflation rate, lower investments, low interest rates and recurring risks of asset bubbles. The causes of this episode of low productivity growth were hotly debated and may turn out to be mostly down to temporary factors following the burst of the dot.com bubble in 2001 and the financial crisis in 2007/2008. Episodes of low growth have occurred in the past, sometimes even during times of rapid technological change.

This still leaves the mystery of a widening gap over several decades between rapid functional/qualitative increase in performance and functionality in many products and services that is not mirrored in national account growth measures. The phenomenon has sometimes been called the Solow paradox. Some economists believe that productivity growth may still occur, but with a significant lag. Others, such as Robert Gordon at Northwestern University, argue instead that the pace of innovation is now slower than many believe, and insufficient to offset the growth-suppressing effects of an increasing proportion of older people in the population and macroeconomic imbalances.

One of the conclusions of this paper is that there is in fact substantial productivity growth but in other dimensions than those captured in national accounts. A relatively new and fairly narrow research literature indicates that many innovative improvements of performance/functionality are not only missed by measured GDP but may, in fact, sometimes lower it. While this contention is still controversial among many economists, an influential overview by Martin Feldstein [1] concluded that measurement problems, even within the framework of what GDP intends to measure, have grown to the point where the GDP measure can at best be seen as a minimum measure, with a potentially very high degree of underestimation. In particular, he argued, the importance of innovation was underestimated. We would add that underestimation may have been greatly exacerbated by the pandemic.

Since then a number of studies have also been published that furthermore indicate that significant value creation takes place beyond what national accounts intend to capture through the GDP measure in the form of consumer surplus and environmental and other externalities.

The pandemic has accelerated the kind of digital work that falls under the definition of household production which has never been included in GDP, and the kind of digital consumption with a zero price tag which is not counted either. Perhaps more importantly the pandemic has underlined the importance of health-related innovation whose benefits also are rarely registered in GDP. Similarly, the value generated by climate-oriented innovations are largely excluded. More generally, efforts to prevent or prepare for calamities are not well captured in GDP or other traditional measures of the returns to innovation. 
An Einsteinian "Gedankenexperiment", thought experiment, can illustrate this. Assume that a research group managed to invent a vaccine against all diseases, including cancer and autoimmune afflictions. The result is that more than half the medical sector is wiped out. Close to $10 \%$ of GDP would disappear, at least until unemployed doctors, nurses etc. find something else to do. Should this really be accounted for as an economic disaster as national accounts would do today since they largely ignore quality of health care improvements... or a major improvement for humankind?

\section{THE GAP BETWEEN PERFORMANCE DEVELOPMENT OF DIGITAL SYSTEMS AND REGISTERED VALUE ADDED}

The most well-known quantified model that describes technological performance enhancement is Moore's law, which states that the number of transistors in computer chips has doubled every second year, followed by the corresponding computing performance increase.

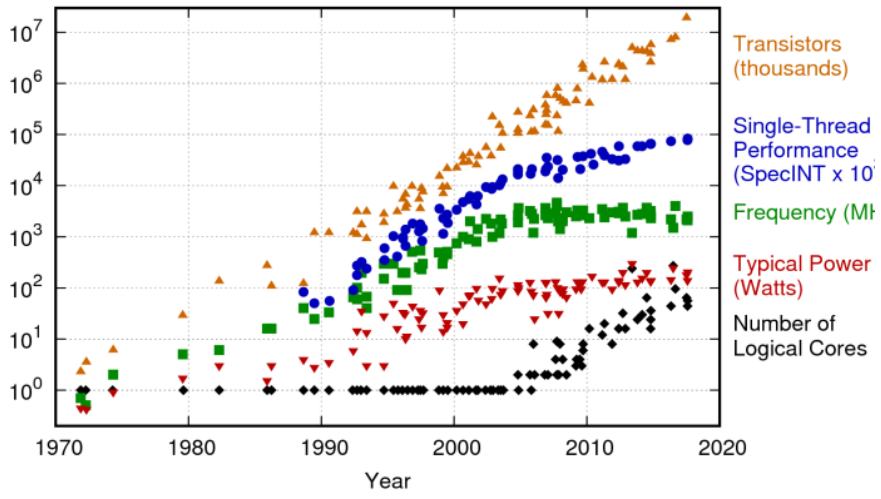

Fig 1. 48 Years of Microprocessor Trend Data [2].

The rapid development of electronics is behind the qualitative advance in many other areas ${ }^{1}$. For example, the price of a cell phone in the early 1990s was equal to or higher than today, while performance and functionality are not comparable. The processor in an iPhone today has higher computing performance than a Cray 2, which was the fastest supercomputer when digital cellular telephony was introduced in the beginning of 1990s. At the time, a Cray 2 cost approx. 20 - 30 Million USD and consumed $200 \mathrm{~kW}$ electric power. Other areas of technology show similar trends and have together contributed to the rapid pace of digitalization, such as the development of optical and photonic technologies resulting in fiber optic cables that are the backbone of almost all communication networks.

\footnotetext{
${ }^{1}$ Bret Swanson [3] gives a good description of the technical gains in "Moore's Law at 50".
}

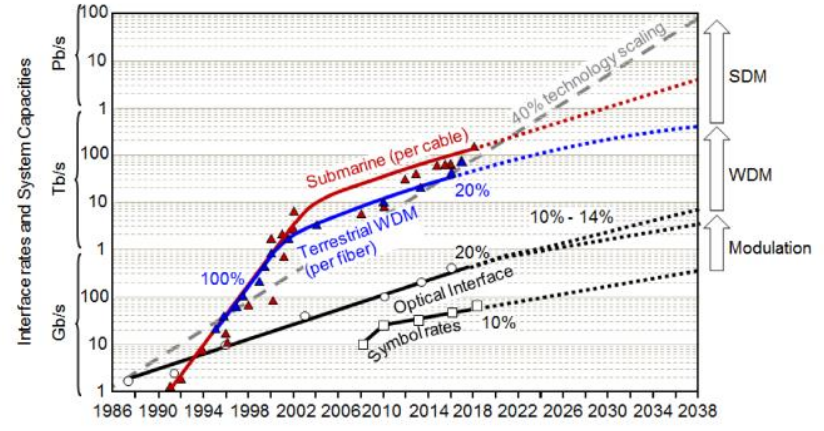

Fig 2. Fiber-optic transmission and networking: the previous 20 and the next 20 years [4].

However, the exponential performance growth of the technologies, fundamental to digitalization, has not been reflected in the revenue of the leading companies. Examples include Intel, a leading company in the computer chip industry, and Ericsson, a leader in the mobile telephony infrastructure. The performance of their products increased $10^{5}-10^{6}$ times since 1990. During that time, their markets have grown significantly and have been characterized by some oligopoly, with few competitors. Nevertheless, the revenue of these companies increased only few times between 1990 and today and the profits are rather normal in the business world.

Similarly, the quality improvement imputed to the electronics sector in European and American national accounts is only about 300 percent since 1990 .

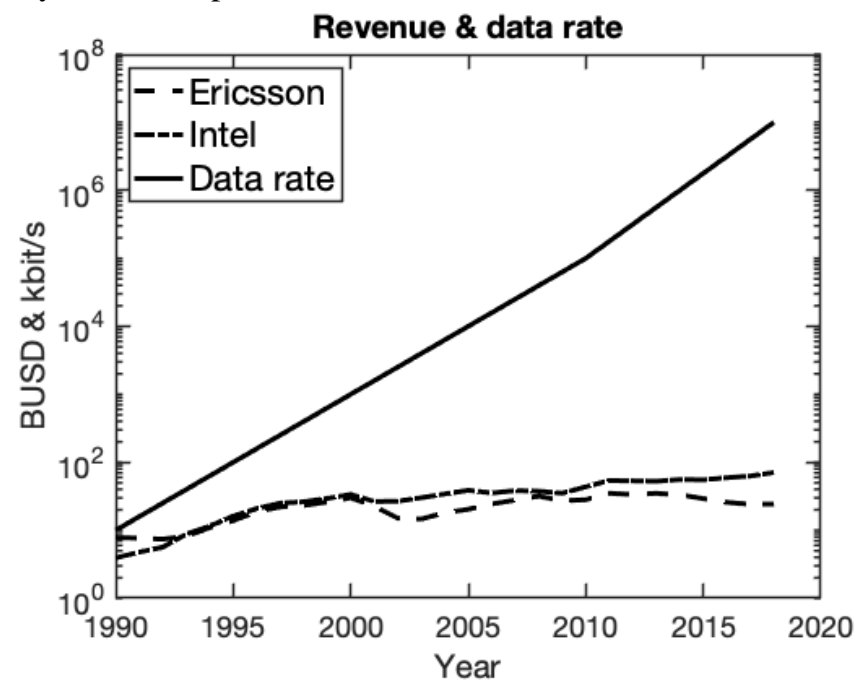

Fig. 3 Revenue for Ericsson and INTEL (BUSD) and bit rates in digital cellular networks

The increase in performance of the technologies necessary for digitalization has given rise to technology platforms in the form of computers, telephones, data centers, embedded systems and communication networks which, together with other innovations and research results, have resulted in a plethora of products and services that improve and reduce the cost to both consumers and businesses in many sectors, mainly outside of 
the ICT sector itself. ICT innovations can thus enable growth in other industrial sectors.

That innovators capture little of the registered value added they generate is well established. ${ }^{2}$ For example, according to Nordhaus [5] innovators only earned 2,2 percent of the contribution to GDP generated by their innovations, in a large study of innovations in the US during 1948-2001. On top of that, however, there are worrying signs that GDP measures capture less and less of value creation that innovations give rise to.

If the performance increase on the order of $10^{5}$ also translated into a corresponding value creation for consumers, and inventive companies such as Ericsson or Intel had pocketed a mere $1 \%$ of this, then the companies' revenue should have increased by $100,000 \%$. As shown above there are no signs of such gain during the relevant time period. This shows that it is difficult for companies to realize the value of the increased performance of their products.

Innovative products and services cannot be decoupled from the performance of the underlying technologies but constitute an additional functional layer. This means that the huge increase in performance landed in the pockets of consumers, sometimes literally in the form a 1990s supercomputer in our purse or pocket.

Indirectly the greater computing power has enabled even faster technological advance in other fields. For example, the diagram below shows how the cost of scanning a human genome has tumbled even faster than would have been predicted by Moore's law.

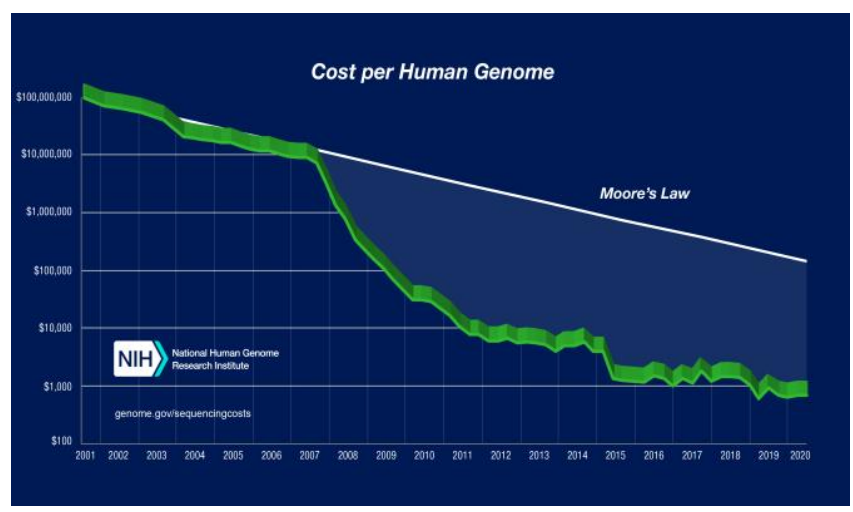

Fig. 4 Cost per Human Genome

\section{A. How GDP is affected by innovations}

To systematize the value creation of innovations, the various mechanisms are shown in table I below. The starting point is that an R\&D effort leads to innovation that is defined in terms

\footnotetext{
${ }^{2}$ A ground-breaking study was by Griliches [6].

${ }^{3}$ Note that the R\&D effort itself is in national accounts sometimes treated as a cost, sometimes as an investment and sometimes as value added depending on the circumstances. Here we focus on the value of the resulting innovations.
}

of a functional improvement. ${ }^{3}$ Here it is assumed that the innovation would not have emerged during a certain time period without a specific R\&D effort that enabled the innovation.

Such an investment in innovation should eventually increase measured GDP through three channels: 1) Greater value added in the innovating firm, 2) Greater value added in other firms that benefit from the innovation and 3) Increase in value added due to follow-up innovations made possible by the original innovation.

Yet much of that value is not captured by official statistical agencies. The table below outlines the main issues. ${ }^{4}$

TABLE I

VALUE CREATION THAT IS MOSTLY NOT REGISTERED IN GDP EVEN THOUGH IT SHOULD $\mathrm{BE}$

\begin{abstract}
Value creation through new products that replace
\end{abstract} old ones is rarely registered

Quality improvements are roughly estimated for products and hardly measured at all in services

Quality improvements in publicly financed services are not registered at all

Immaterial investments are only partially registered

\section{B. Value creation beyond GDP}

Beyond the issues mentioned above, economists have been well aware of the fact that the definition of GDP excludes huge chunks of value creation that may have become increasingly important.

For example, consumers now have access to a large amount of apps / services that are either free or at a low cost. There is no production cost for these programs, only development cost, and distribution is virtually free. To the extent that these increase the consumer surplus, they are not included in GDP growth. These and similar issues are listed in table II below.

\footnotetext{
${ }^{4}$ Several reviews of the empirical literature on these have been published that corroborate the import of the omissions, e.g. [1].
} 
TABLE II

INNOVATION'S VALUE CREATION NOT COVERED BY GDP
Consumer surplus

Value of household production

Consumers' time optimization

Zero-priced goods and services

Environmental gains, lower risk of pandemics and other externalities
Consumers' valuation beyond the price they pay can be high but is beyond the definition of GDP.

Many digital platforms are based on user input, a form of household production.

Digital services often allow more efficient time use of consumption.

Many digital services are free, apart from the cost of seeing ads. These provide value beyond the definition of GDP.

For example, regulations that reduce the risk of pandemics spreading or of global warming will appear as a cost in GDP-accounting with no registered gain.
Digitalization has changed consumption patterns, and consumer-driven innovations have expanded the content supply provided via the Internet. E-commerce has grown rapidly since the turn of the millennium. It has become mobile. Digital platforms replaced traditional intermediaries and many established industries were challenged.

A supply shock of digital services began with price models characterized by a fixed cost such as a subscription with zero marginal price, or completely free digital services. Spotify and Netflix are a couple of examples of the former and Facebook, YouTube and Google of the latter,, often in exchange for personal data about online activities which can be used to generate revenues, e.g. as Google has done for online advertisements.

A series of empirical studies confirm that value creation beyond what is covered by the definition of GDP appears to be significant and rising due to the vast expansion of free digital content and digital household production. ${ }^{5}$

A further, and separate, value creation beyond what is registered in GDP occurs in externalities and regulations that affect these. For example, economists have always been aware of the fact that production that harms the environment involves a cost that is not registered in GDP. Some remedial measures may be counted. If consumers, for example, choose more expensive cars that emit less this choice will show in up in national accounts in the same way as if they had chosen a better sound system. But if governments implement regulations that force a factory emit less at higher cost, the consequence will instead be lower GDP.

Similarly other regulations intended to reduce risks, such as lockdowns during a pandemic, lower GDP. A consequence of the pandemic in combination with the climate issue is that regulations intended to mitigate future risks are likely to

\footnotetext{
${ }^{5}$ For example [7].
}

become more commonplace and impose greater costs on production. This will make it look like countries that are doing the most to avert future risks are the least successful, even though their regulation also tends to drive innovation.

These examples show that GDP-calculations miss much value creation, especially as societies digitalize.

\section{C. $\quad$ Value creation in the metaverse}

In the coming decades, digitalization may change shape again. Autonomous vehicles, virtual realities, the "internet of things", self-learning robots, digital doctors and teachers can create values that also largely grow alongside what is measured in GDP. The question is whether completely different measures of economic development are then needed.

All large digital platforms are engaging in huge investments in the metaverse, a virtual space where people live and work. To this end Facebook is investing in a hardware platform for "virtual reality" (VR) and "augmented reality" (AR), which serves users real-time-adapted digital information as they survey the real world through smart spectacles and the like. This is one part of building a "creator economy", where people make money from digital work. If users start spending 35 hours a week immersed in the Facebook semi-virtual world, rather than 35 minutes a day in front of a normal laptop, the impact on how value creation is registered could be huge. While such a move from physical workplaces to work at home is partly just a continuation of previous trends it can have huge consequences of value creation shifts to forms that are not captured by GDP or other official measures. Most importantly this will occur if more value creation falls under the definition of "household production" and more digital consumption carries a zero price. As we have seen above, such changes are not captured by traditional GDP-measurements.

\section{HOW CAN THE VALUE OF INNOVATIONS BE BETTER MEASURED}

A reasonable measure of country's economic success, and not least its innovation policies, requires new and better measures of value creation. The pandemic has precipitated the need for alternative measures, especially for innovative countries that digitalize evermore.

While innovation policy may be most in need of new measures, they are important for monetary and fiscal policies as well. Underestimation of growth may for example nudge central banks to overstimulate and risk inflating asset bubbles? ${ }^{6}$

Underestimation of how prosperity evolves and to whom it accrues also has important implications for other variables in economic policies, such as poverty and economic inequality. A cell phone and a very limited subscription fee gives access to

\footnotetext{
${ }^{6}$ See [8] for an example of a study that analyzes how inflation statistics are affected by some of the measurement problems discussed here.
} 
encyclopedias, almost all of the world's music, maps, a video selection larger than previous video stores and thousands of other applications. As this is not measured correctly in traditional GDP-calculations it means that true consumption of low- and high-income earners may have evolved, and continue to evolve, quite differently from what national account statistics convey.

\section{A. Measuring value creation of innovations in new ways}

It is possible to systematically measure performance and functionality, at least in some dimensions. ${ }^{7}$ One area where this is already partially done in part is the environment and climate.

Environmental accounts are structured based on national accounts and report national environmental statistics and economic statistics in a common system. Environmental data are systematized according to the same industry division and the same end uses as economic data. The main purpose of systematizing statistics in this way is to analyze the links between economics and the environment. The areas that have been included so far are for example emissions to air and water, waste, energy use, material flows, chemicals, environmental protection costs, environmental companies, environmental taxes and environmental subsidies, and natural resources.

National accounts measure the gross domestic product in two different ways; one from supply and the other from demand. The environmental accounts measure the same thing from an environmental perspective. If the production perspective answers the question "Who releases?" then the consumption perspective answers the question "For whom are the emissions made?" The method for producing statistics is based on inputoutput analysis where the framework of the environmental and national accounts is used.

Similar methods could be used elsewhere, capturing how households produce and consume in virtual worlds, and how resources are used to prevent and adapt to health and environmental risks.

\section{B. Introduction of new indices to complement GDP measure}

We propose an introduction of new measurable nonmonetary, technology-based, growth indicators to complement GDP to give a more comprehensive way to evaluate economic growth.

The increase in performance in electronic products that comply with Moore's law and which form the basis of the entire digital economy and automation could be measured in the equivalent of index of performance improvements akin to that used to illustrate Moore's law. Similar indices could be developed for technologies other than electronics where of course the main key parameters to be measured are different. For products that consist of mixed technologies, the total becomes a mixed index depending on their share in the finished product.

\footnotetext{
${ }^{7}$ See [9] for an example of suggestions to measure virtual household production.
}

For services that have been created as a result of digitalisation, even those that are not captured by the GDP measure, the volume of data in the communication networks can be measured, since these services are based on communication. Such indices would capture both human activity and automated activity such as Internet of Things .

The proposed indices are directly measurable and not based on subjective assessments such as quality or value. At the same time, they reflect the growth of the digital economy regardless of where it is created. As digital technology grows in more industries, they are becoming more universal.

\section{ChOOSING GROWTH TRAJECTORIES}

Changing growth measures such as GDP is slow business because statistical agencies also try to maintain comparability with other countries and with historical data. In contrast, adding measures of the kind we outline here is easier. Yet the consequences could be stark. Choosing and refining complementary measures is not just a technical exercise. Rather it would instigate a debate about growth priorities. How much should a country invest in innovations that are poorly captured by traditional GDP measures such as in medicine, health care, climate technology, digitalization of public services and infrastructure, and risk avoidance?

Such a debate and measurable progress would probably also encourage investments in technological leaps or grand challenges in these areas. The impact on innovation policy could be profound and might help the world to be much better prepared for future pandemics or other calamities. 


\section{REFERENCES}

[1] M. Feldstein, "Underestimating the Real Growth of GDP, Personal Income, and Productivity." Journal of Economic Perspectives-Volume 31, Number 2-Spring 2017-Pages $145-164$.

https://pubs.aeaweb.org/doi/pdfplus/10.1257/jep.31.2.145

[2] Original data up ta the year 2010 collected and plotted by M. Horowitz, F. Labonte, 0. Shacham, K. Olukotun, L. Hammond, and C. Ballen New plot and data collected for 2010-2019 by K. Rupp.

[3] B. Swanson, American Enterprise Institute, November 2015.

[4] Winzer, P, D. Neilson, och A. Chraplyvy (2018) Fiber-optic transmission and networking: the previous 20 and the next 20 years, Opt. Express 26, 24190-24239.

[5] W. D. Nordhaus "Schumpeterian profits in the American economy: Theory and measurement," NBER Working Paper No. 10433 (National Bureau of Economic Research, Cambridge, MA).

[6] Z. Griliches "The Search for R\&D spillovers," Scand. Journal of Economics 94, Supplement, 29-47, 1992.

[7] E. Brynjolfsson, A. Collis, W. E. Diewert, F. Eggers and K. J. Fox " Measuring the Impact of Free Goods on Real Household Consumption," January 10, 2020. AEA Papers and Proceedings, 110 (Mai 2020). SSRN abstract 3517017.

[8] D.M. Byrn and C. A. Corrado "The Increasing Deflationary Influence of Consumer Digital Access Services. Finance and Economics Discussion Series 2020-021." Washington: Board of Governors of the Federal Reserve System. https://doi.org/10.17016/FEDS.2020.021.

[9] E. Brynjolfsson, E., A. Collis, W. E. Diewert, F. Eggers och K. J. Fox "GDP-B: Accounting for the Value of New and Free Goods in the Digital Economy," NBER Working Paper No. 25695. Mars 2019. SSRN abstract 3356697.

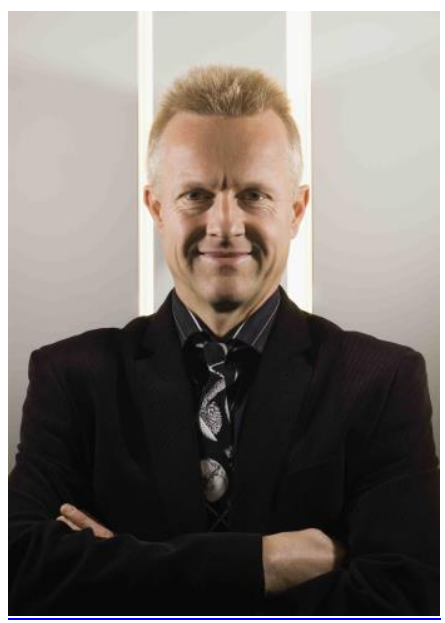

Stefan Fölster (Director, Better Future Economics) received a D.Phil. degree from Oxford in 1987. He has since been professor of economics at several institutions, among them the Royal Institute of Technology in Stockholm, Sweden. He has also been chief economist at the Confederation of Swedish Enterprise. He was director of the Swedish Trade Institute and the Reform Institute in
Stockholm. He has authored books and many publications in the fields of public economics, entrepreneurship, innovation policy and digitalisation

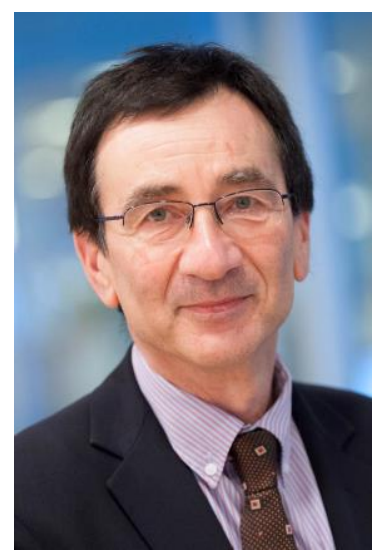

Andrej Litwin received a Ph.D degree in Solid State Physics from Lund University, Sweden, in 1986. He has been a professor in Nanometer Technology at Lund University and a professor in High Speed Electronics at Chalmers University of Technology. $\mathrm{He}$ also has a long experience of semiconductor industry, with 22 US patents, and of R\&D financing from European Commission and The Swedish Governmental Agency for Innovation Systems, Vinnova. 